\title{
Seroprevalence of Hepatitis A Antibodies in a Group of Normal and Down Syndrome Children in Porto Alegre, Southern Brazil
}

Cristina Targa Ferreira, Júlio César Leite, Adriano Nori R.Taniguchi, Sandra Maria G. Vieira, Jorge Pereira-Lima and Themis Reverbel da Silveira
Graduate Program in Gastroenterology, Clinical Hospital of Porto Alegre, Federal University of Rio Grande do Sul, Porto Alegre, Brazil

The high incidence of Hepatitis A and B in institutionalized patients with Down Syndrome (DS) is not fully understood. Under poor hygienic conditions, immunological alterations might predispose individuals to these infections. Sixty three DS children between 1 and 12 years old living at home with their families were examined for anti-HAV and compared to age-matched controls (64 healthy children). This cross-sectional study was carried out from May, 1999, to April, 2000, at the Hospital de Clínicas of Porto Alegre, southern Brazil. Groups were compared in terms of age, sex, skin color, and family income ( $>$ R $\$ 500$ and $<R \$ 500 /$ month) by the chisquare test, with Yates' correction and for the prevalence of anti-HAV (Fisher's exact test). In the DS group $(n=63)$, the mean age was $4.4 \pm 3.3$ years, $94 \%$ of the patients were white and $51 \%$ were female. Family income was $\leq R \$ 500$ /month in 40 cases $(63 \%)$. In the control group $(n=64)$, the mean age was $4.8 \pm 2.7$ years, $81 \%$ of the patients were white and $56 \%$ were female. Family income was $\leq R \$ 500$ in 20 patients $(31 \%)$. DS children's families had a significantly lower income $(\mathrm{P}<0.0005)$. In the DS group there were 6 positive $(9.5 \%)$ anti-HAV cases, and all came from low-income families (less than $\mathbf{R} \$ \mathbf{5 0 0}$ / month). In the control group, 3 cases $(4.7 \%)$ were positive for anti-HAV (two were from a low-income family and one was from a higher income family). These differences were not significant. Our data indicate that Hepatitis A is not a special risk for mentally retarded DS outpatients, even in a developing country like Brazil.

Key Words: Down syndrome, hepatitis A, seroprevalence.

Hepatitis A virus (HAV) infection is still one of the most common causes of acute liver disease and is a major public health problem in many developed and developing countries worldwide [1,2]. As the HAV transmission cycle is directly influenced by sanitation, high prevalences of HAV infection have been associated with low socioeconomic levels and poor hygiene conditions [3].

Struchiner et al. [4] have suggested that epidemiological studies on the prevalence of anti-HAV Received on 15 April 2002; revised 17 September 2002. Address for correspondence: Dr. Cristina Targa Ferreira. Rua Pedro Weingartner n ${ }^{\circ} 105$ ap. 202 - Porto Alegre - RS - Brazil. Zip code: 90430-140. Phone: (51) 3331-3295. Fax number: (51) 3388-4369.E-mail: cristina@qbnet.com.br

The Brazilian Journal of Infectious Diseases 2002;6(5):225-231 (C) 2002 by The Brazilian Journal of Infectious Diseases and Contexto Publishing. All rights reserved. $1413-8670$ provide extremely useful information about the incidence rates of infection or disease, and consequently about the development of sanitary conditions at a given location. Improved public health programs and sanitary conditions have a positive impact on the epidemiological pattern of HAV infection in developing countries [5]. Tapia-Conyer et al. [5] reported a change from high to intermediate endemicity in the epidemiology of HAV infection in Latin America.

The assessment of the prevalence ofHAV infection in a population is extremely important for the determination of strategies that should be implemented in order to control infection [5, 6]. In Brazil, studies show varying prevalences in different regions and according to the socioeconomic level of each population [5-8].

Until very recently, the primary methods employed in the prevention of HAV infection have been 
improvement of hygienic conditions and passive immunization with immunoglobulin, to provide shortterm protection. The ability to grow HAV in cell cultures has resulted in the development of highly immunogenic hepatitis A vaccines with only minor side effects [9, 10]. Active immunization can provide long-term protection for the individual against HAV; from a public health perspective, vaccine provides the means to effectively control this disease [10].

The use of hepatitis A vaccine is recommended for populations at increased risk for acquiring the infection or for its adverse consequences, including children living in areas with high and intermediate endemicity and those who belong to communities at high risk for infections and epidemics [10-13].

Children with Down syndrome (DS) have both cellular and humoral immunodeficiencies, and usually attend day-care centers and special schools (a major source of transmission). Theoretically, they are more susceptible to infections and their complications $[14,15]$.

To distinguish between environmental and endogenous (immunological) influences DS children living at home with their families were studied for the occurrence of Hepatitis A. Healthy children from the same region were studied as controls. This study was performed as a step prior to Hepatitis A vaccination.

\section{Material and Methods}

A cross-sectional seroepidemiological study was performed during one year (May, 1999, to April, 2000) with 127 children between 1 and 12 years of age. The patients were divided into two groups: DS children and normal children.

DS children were selected among patients from the Genetics Service at the Hospital as Clínicas de Porto Alegre (HCPA) [16], Brazil, and from a special school for mentally retarded children. All patients attended public, day-care centers and special schools for at least 4 hours/day. In addition, all children attended the Association of Parents and Friends of Mentally Challenged Children (Associação dos Pais e Amigos de Excepcionais - APAE) at least twice a week for group activities. The children that were selected lived at home with their parents (non-institutionalized). Diagnosis of DS was established based on clinical criteria and chromosome studies (karyotype) [16].

The control group of healthy children was constituted of sons and daughters of HCPA employees and by brothers and sisters of HCPA patients. Children up to 6 years old attended the Vera Fabrício Carvalho day-care center at HCPA; older children attended public schools.

Exclusion criteria were age below 12 months or above 12 years, inpatients or outpatients requiring continuous medical care, HIV-positive patients, patients with chronic diseases associated with immunosuppressive treatment, previous history of HAV infection or previous administration of the hepatitis A vaccine, and patients whose parents refused to sign the informed consent form.

All of the selected children were seen at the outpatient service of the hospital; on this occasion, patient history was assessed, and a physical examination and blood collection were performed. All patients had good general health and were involved in normal activities, with no health restrictions.

For the laboratory analysis, $5 \mathrm{ml}$ venous blood samples were obtained from each child. These samples were centrifuged and frozen at $-20 \%$ for later processing. Total anti-HAV antibodies were determined by the microparticle enzyme immunoassay (MEIA, HAVAB, AXSYM System, Abbott Laboratories); all tests were performed in the same laboratory (Weinmann, Porto Alegre, Brazil). Results were classified as positive or negative; results in the gray zone (indeterminate) were repeated or discarded. All patients were informed about the test results, either by phone or personally. Parents of children with positive anti-HAV tests were informed about the meaning of the results. Hepatitis A vaccine was offered to all children with negative results; it should be administered up to 15 days after blood collection.

Family income was assessed by means of a questionnaire given to all guardians. Individuals with a family income below R \$ 500/month were classified as pertaining to a low socioeconomic level. 
The sample size was determined by our objective to find 50 susceptible children (negative for anti-HAV) in each group, who could be vaccinated against hepatitis A, later, on another occasion.

The population of children was stratified according to age, sex, skin color, and family income. Means, medians and standard deviations for age and family income were calculated. Groups were compared in terms of family income ( $>\mathrm{R} \$ 500$ and $<\mathrm{R} \$ 500)$ by the chi-square test, with Yates' correction. Fisher's exact test was used to test for the significance of positivity of the anti-HAV test. The significance level was 0.05 .

The research protocol was approved by the Ethics Committee of HCPA. Written informed consent was obtained from all parents or guardians of the selected children. The study followed the guidelines set in the Helsinki Declaration.

\section{Results}

The mean age of the DS group was $4.4( \pm 3.3$ years). Forty-eight children (76\%) were up to 6 years old, 59 (94\%) were white and 32 (51\%) were female. Family income in this group varied from R\$ 136 (minimum wage) to R $\$ 3000$ per month, with a mean of $\mathrm{R} \$ 589( \pm \mathrm{R} \$ 490)$. Family income was $\leq \mathrm{R} \$ 500$ / month in 40 cases $(63 \%)$; only one family had an income of R\$ 3000/month; all the others received $<\mathrm{R} \$ 1800$. The mean age of the normal, control group was 4.8 ( \pm 2.7 years). Forty-nine (77\%) children were up to 6 years old, 52 children (81\%) were white and $36(56 \%)$ were female.

In this group, family income varied from $\mathrm{R} \$ 150$ to $\mathrm{R} \$ 3000$; the mean was R\$ $1100( \pm 828)$. family income was $\leq \mathrm{R} \$ 500$ for 20 patients $(31 \%)$.

In the comparison of these two groups, families with DS children had a significantly lower income: $75 \%$ earned $<$ R\$ $600 \quad(\mathrm{P}<0.0005$; chi-square, Yates' correction). This percentage was only $44 \%$ in the control group (Table 1).

Of the 63 patients with DS, six $(9.5 \%)$ had antiHAV antibodies. One of them was 5 years old, two were 6 years, two were 7 years, and one was 11 years old. None of the positive children was black; five were male. The characteristics of the anti-HAV positive children are shown in Table 2.

All children with HAV antibodies came from families that earned $\leq \mathrm{R} \$ 500 /$ month or that pertained to a low socioeconomic level $(\mathrm{P}<0.08$; Fisher's exact test). If we consider all $40 \mathrm{DS}$ children that came from families with a low socioeconomic level, 6 tested positive (15\%); in the same group of DS children from a higher socioeconomic level, there was no positive case $(\mathrm{P}=0.08)$.

Out of the 64 normal children, three (4.7\%) were positive for anti-HAV. Age varied from 7 to 9 years; two children were black; all three were male. Family income was $\mathrm{R} \$ 200, \mathrm{R} \$ 400$ and $\mathrm{R} \$ 600$, respectively. Among the control group positive children, two were from a low socioeconomic level $(10 \%)$, and the third one was from a higher level $(2.3 \%)(\mathrm{P}=0.23)$.

When both groups were compared in terms of positive cases of anti-HAV, no significant difference was observed ( $\mathrm{P}=0.32$; Fisher's exact test). Mean age of positive children was 7.3 years; overall mean age was 4.6 years.

\section{Discussion}

$\mathrm{HAV}$ is primarily transmitted via the fecal-oral route, by personal contact, or through the ingestion of contaminated foods or water. Racial, ethnical, and geographical differences in HAV transmission rates actually reflect variations in the socioeconomic level and resulting life conditions of patients [9, 10]. Prevalence of anti-HAV is inversely proportional to the per capita income of the population [7-10, 17]. In Brazil, although a great part of the population pertains to a low socioeconomic level, there are many variations in sanitary and hygienic conditions.

There are some studies showing high prevalence rates among less privileged populations and groups of susceptible people living within the same community [6-8]. Costa Clemens et al. [8] stated that in Brazil, seronegative children, teenagers, and young adults present a risk as high as that of people who travel to 
Table 1. Characteristics of the two groups of children

\begin{tabular}{|c|c|c|}
\hline Characteristic & $\begin{array}{l}\text { DS children } \\
\quad(n=63)\end{array}$ & $\begin{array}{l}\text { Normal children } \\
\qquad(\mathrm{n}=64)\end{array}$ \\
\hline \multicolumn{3}{|l|}{ Age } \\
\hline Mean & 4.4 & 4.8 \\
\hline SD & 3.3 & 2.7 \\
\hline Median & 4 & 4.5 \\
\hline Up to 6 years & $48(76)$ & $49(77)$ \\
\hline \multicolumn{3}{|l|}{ Skin color } \\
\hline White & $59(94)$ & $52(81)$ \\
\hline \multicolumn{3}{|l|}{ Sex } \\
\hline Male & $31(49)$ & $28(44)$ \\
\hline \multicolumn{3}{|l|}{ Family income } \\
\hline Mean & 589 & 1100 \\
\hline SD & 490 & 828 \\
\hline Median & 450 & 900 \\
\hline Variation & 136 to 3000 & 150 to 3000 \\
\hline$\leq \mathrm{R} \$ 500$ & $40(63)$ & $20(31)^{*}$ \\
\hline$>\mathrm{R} \$ 500>\mathrm{R} \$ 1000$ & $15(24)$ & $19(30)$ \\
\hline > U\$ 1000 & $8(13)$ & $25(39)$ \\
\hline Total cases of positive anti-HAV & $6(9.5)$ & $3(4.7)$ \\
\hline
\end{tabular}

Table 2: Characteristics of the anti-HVA positive group

\begin{tabular}{lcccc}
\hline Group & Age (years) & Sex & Skin color & Family income(R\$) \\
\hline DS & 11 & M & W & 500 \\
DS & 6 & M & W & 300 \\
DS & 7 & F & W & 500 \\
DS & 7 & M & W & 400 \\
DS & 5 & M & W & 500 \\
DS & 6 & M & W & 500 \\
Control & 7 & M & B & 200 \\
Control & 8 & M & W & 400 \\
Control & 9 & M & B & 600 \\
\hline
\end{tabular}

DS- Down Syndrome; M-male; F-female; B-black; W-white. 
endemic areas, since they are not protected from HAV infection and are under continuous risk of exposure. These authors found over $40 \% \mathrm{HAV}$ infection in children from 6 to 10 years of age pertaining to a low socioeconomic level in Porto Alegre, Brazil [8].

Two studies, one performed in Porto Alegre [7] and the other in São Paulo [6], Brazil, clearly show the disparity in the prevalence rates of two socioeconomically distinct populations, living in the same area. This co-existence of high and low prevalences suggests that HAV is always present in the environment, which make our anti-HAV negative populations even more susceptible [6-8].

The two groups of children in our study may be considered at high risk for acquiring HAV infection. This is due to two main factors: age and socioeconomic level. In addition, both groups were composed of children attending public, day-care centers and special schools for DS children, which constitute an important source of hepatitis A in many communities $[3,9,10]$.

Zanetta et al. [18] found a mean age for the occurrence of infection is 6.7 years in populations with intermediate endemicity for HAV. So, the strategy of vaccinating children before they start school should provide protection prior to exposure. In our study $76 \%$ of the children in the Group I were at preschool age and in Group 2,77\%. The mean age of infected children was 7.3 years.

In the total sample, 60 children $(47 \%)$ belonged to families earning $<\mathrm{R} \$ 500 /$ month; $74 \%$ of the families earned $\leq \mathrm{R} \$ 1,000 /$ month.

Our results showed a low prevalence of anti-HAV even in children pertaining to high risk groups and to low socioeconomic levels. Although our children constituted a high risk group, the prevalence of antiHAV was low. This may be a result of the improved sanitary conditions observed in the southern part of Brazil [7]. In addition, the prevalence of anti-HAV was extremely low in both normal and DS children, and did not show a higher predisposition of non-institutionalized DS children for HAV infection when compared to normal children. Renner et al. [19] also found that HAV is not a special risk for non-institutionalized DS children. On the other hand, a study performed by Smuzness et al.[20] reports that many closed communities formentally retarded individuals are hyperendemic for hepatitis $\mathrm{A}$, and that the formation of anti-HAV antibodies is not strongly affected by immunodeficiency or immune immaturity. The slightly lower prevalence found in our normal patients is probably related to their higher socioeconomic level, and not to the absence of DS.

The anti-HAV prevalences were not significantly different in DS versus normal children $(9.5 \times 4.7 \%$, respectively), probably due to the small sample size. Several reasons have been indicated for a higher prevalence of positive anti-HAV cases among DS patients [19]. In our study, this higher prevalence was probably due to the lower family income observed in this group; this finding is in accordance with other studies that report an association between HAV and family income $[4-6,10]$.

In places where hygiene and sanitary conditions are adequate, specific groups may have a relatively high risk for HAV infection. Small epidemics are occasionally seen in schools, day-care centers, and institutions for mentally retarded children, since these patients present characteristics that are associated with HAV infection, such as oral behavior, urinary and fecal incontinence, and poor personal hygiene $[9,10]$. In the United States, 10 to $15 \%$ of the reported cases of HAV infection occur in day-care centers and schools [10].

Children attending day-care centers and special schools have increased HAV transmission rates [3]. The habits of these children and the unfavorable hygiene conditions found in these settings make dissemination of the virus easier; as a result, the infection is transmitted to other children and also to the adults that are in contact with them.

In our study, DS children also attended day-care centers and special public schools; however, they did not have a high prevalence of HAV.

Children with DS present both humoral and cellular immunodeficiency, with variations in relation to age $[14$, 21]. These children are more susceptible to infections during the first two decades of life; in addition, they have a higher infection-related mortality rate [14,21]. DS patients present zinc deficiency, thymic abnormalities, functional alterations in T- and B- 
lymphocytes, reduced production of some cytokines, such as IL-2, and a higher frequency of autoantibodies [15]. The specific humoral immune response is low in cases of antibodies to some viral antigens, such as influenza $[15,22]$. However, other studies do not show any difference between DS and control children in their antibody response to viral protein antigens $[15,23]$.

Other studies have shown that children with DS frequently carry hepatitis B surface antigen ( $\mathrm{HBsAg}$ ) $[15,24]$; though our population did not have a high infection rate. This suggests inadequate immunological handling of the hepatitis $\mathrm{B}$ virus (HBV) in DS patients, which can be explained by an abnormal immune response [15]. A Spanish group studied 302 mentally retarded children (both DS and non-DS patients) and concluded that DS children acquire HBV more easily; according to the authors, transmission usually takes place at school [24]. Renner et al. [19] agree that HBV is hyperendemic even in non-institutionalized children.

The similarities between the epidemiology of hepatitis A and poliomyelitis suggest that mass vaccination of appropriate susceptible populations may substantially decrease the incidence of the disease, eliminate virus transmission, and ultimately eradicate HAV infection $[9,10]$. The similarities between the epidemiology of these two infections indicate that a reduction in disease incidence can be achieved once persons in age groups that have the highest rates of HAV infection and who serve as a reservoir of infection are immunized $[9,10]$. Because of their critical role in HAV transmission, children should be a primary focus of immunization strategies to lower disease incidence [11]. Because most children have asymptomatic or unrecognized infections, they play an important role in HAV transmission and serve as a source of infection for others $[10,25]$.

With the commercial availability of the hepatitis A vaccine, the performance of prevalence studies aimed at determining which populations should be vaccinated has become opportune and relevant [17]. It is possible to calculate vaccination costs and to establish target groups as well as the lower age limit and prevalence rates for prevaccination screening [26].
DS children respond to the hepatitis B vaccine, but with lower levels of antibodies [15]. The response of these children to the hepatitis A vaccine is not known.

The high cost of available vaccines, the financial restrictions in the public health system, and the seroepidemiological patterns of $\mathrm{HAV}$ infection justify studies on the efficiency of systematic detection of anti-HAV prior to vaccination, in order to establish the minimum prevalence required for the determination of disease markers $[8,17]$. In any case, prevaccination screening is indicated for groups with high infection rates. On the other hand, mass vaccination would be more effective in risk groups with low infection rates.

In summary, although our patients constituted a high risk group, prevalence rates of anti-HAV positivity were low and DS was not associated with increased risk for acquiring HAV infection. We suggest that prevaccination screening for anti-HAV should be done in our city and that vaccination of susceptible patients should be carried out in preschool-aged children.

\section{Acknowledgements}

We are grateful for the editorial support provided by the Graduate Research Group at the Hospital de Clínicas de Porto Alegre and to Weinmann Laboratories for the anti-HAV assays.

\section{References}

1. Das A. An economic analysis of different strategies of immunization against Hepatitis A Virus in developed countries. Hepatology 1999;29:548-52.

2. Chalasani N., Gitlin N. Acute hepatitis A: what's new with it? Am J Gastroenterol 1998;93:2305.

3. Queiroz D.A.O., Cardoso D.D.P., Martelli C.M.T., et al. Risk factors and prevalence of antibodies against HAV in children from day-care centers in Goiania, Brazil. Rev Inst Med Trop São Paulo 1995;37(5):427-33.

4. Struchiner C.J., Almeida L.M., Azevedo R.S., Massad E. Hepatitis A incidence rate estimates from a pilot seroprevalence survey in Rio de Janeiro, Brazil. Intern J Epidemiol 1999;28:776-81. 
5. Tapia-Conyer R., Santos J.I., Cavalcanti A.M., et al. Hepatitis A in Latin America: a changing epidemiologic pattern. Am J Trop Med Hyg 1999;61(5):825-9.

6. Pinho J.R.R., Sumita L.M., Moreira R.C., et al. Duality of patterns in hepatitis A epidemiology: a study involving two socioeconomically distinct populations in Campinas, São Paulo state, Brazil. Rev Inst Med Trop Sao Paulo 1998;40(2):105-6.

7. Ferreira C.T., Silva G.L., Barros F.C., Pereira-Lima J. Soroepidemiologia da hepatite A em dois grupos populacionais economicamente distintos de Porto Alegre. GED 1996; 15(3):85-90.

8.. Costa Clemens A.S., Da Fonseca J.C., Azevedo T., et al. Soroprevalência para hepatite A e hepatite B em quatro centros no Brasil. Rev Soc Bras Med Trop 2000; 33(1):1-10.

9. Centers for Disease Control and Prevention. Prevention of hepatitis A through active and passive immunization. Recommendations of the ACIP. MMWR 1996;45(RR15):1-31.

10. Centers for Disease Control and Prevention. Prevention of hepatitis A through active and passive immunization. Recommendations of the ACIP. MMWR 1999;48(RR12):1-37.

11. American Academy of Pediatrics. Committee on Infectious Diseases. Prevention of hepatitis A infection: guidelines for use of hepatitis A vaccine and immune globulin. Pediatrics, 1996;98(6):1207-15.

12. Sociedade Brasileira de Pediatria. Indicações - Guia de Adolescência: orientação para profissionais da área médica. Rio de Janeiro, 2000, 60 p.

13. Sociedade Brasileira de Pediatria. Indicações de Vacinas. Disponível em: <http://www.sbp.com.br. Acesso em: fevereiro 2002.

14. Avanzini M.A., Monafo V., De Amici M., et al. Humoral immunodeficiencies in Down syndrome: serum IgG subclass and antibody response to hepatitis $B$ vaccine. Am J Med Genet 1990; 7(suppl):231-3.

15. Ugazio A.G., Maccario R., Notarangelo L.D., Burgio G.R. Immunology of Down syndrome: a review. Am J Med Genet 1990;7(suppl):204-12.

16. Lima G.B., Capra M.E.Z., Frantz B.C., et al. Síndrome de Down: características clínicas, perfil epidemiológico e citogenético em recém-nascidos no HCPA. Revista AMRIGS 1996;40(1):8-13.

17. Queiroz D.A.O., Cardoso D.D.P., Martelli C.M.T., et al. Soroepidemiologia da infecção pelo vírus da hepatite A em "meninos de/na rua" de Goiânia, Goiás. Rev Soc Bras Med Trop 1995;28:199-203.

18. Zanetta D.M.T., Azevedo-Neto R.S., Silveira A.S.B., Nokes D.J. Seroprevalence of hepatitis A in a community of São Paulo, Brazil (abstract) In: 7th International Congress for Infectious Disease (Hong Kong) 10-13 june;1996.
19. Renner F., Andrle M., Horak W., Rett A. Hepatitis A and B in non-institutionalized mentally retarded patients. Hepatogastroenterology 1985;32(4):175-177.

20. Szmuness W., Purcell R.H., Dienstag J.L., Stevens C.E. Antibody to hepatitis A antigen in institutionalized mentally retarded patients. JAMA 1977;237(16):1702-5.

21. Cossarizza A., Monti D., Montagnani G., et al. Precocious aging of the immune system in Down syndrome: alterations of B-lymphocytes, T-lymphocyte subsets, and cells with natural killer markers. Am J Med Genet 1990; 7 (suppl):213-8.

22. Gordon M.C., Sinha S.K., Carlson S.D. Antibody responses to influenza vaccine in patients with Down syndrome. Am J Ment Defic 1971;75:391-9.

23. Hawkes R.A., Boughton C.R., Schroeter D.R. The antibody response of institutionalized Down's syndrome patients to seven microbial antigens. Clin Exp Immunol 1978;31:298-301.

24. Rua Armesto M.J., Ramirez Marin V., Onaindia Ercoreca M.T., et al. Predisposition of Down syndrome to chronic infection with the hepatitis B virus. An Esp Pediatr 1993;38(6):529-31.

25. Staes C.J, Schlenker T.L.,Risk I., et al. Sources of infection among persons with acute hepatitis A and on identified risk factors during a sustained community-wide outbreak. Pediatrics, 2000;106(4):54-60.

26. Navas E., Bayas J.M., Brugera M., et al. Eficiencia de la detección prevacunal de anti-HVA en los programas de vacunación antihepatitis A. Med Clin (Barc) 1995; 105:168-71. 